\title{
Discussion on Teaching and Practice of Software Engineering Major Curriculum Based on Project Guidance
}

\author{
Hong Hui Fan ${ }^{1, a^{*}}$, Hong Jin Zhu ${ }^{1, b}$, Xiao Rong Zhao ${ }^{1, c}$ and Jie Zhang ${ }^{1, d}$ \\ ${ }^{1}$ School of Computer Engineering, Jiangsu University of Technology, Changzhou 213001, China \\ afanhonghui@jsut.edu.cn, bzhuhongjin@jsut.edu.cn, czhaoxr432698@gmail.com, \\ dzhangjie@jsut.edu.cn
}

Keywords: Project guidance; Software engineering; Multilevel curriculum; Professional education; Teaching reform.

\begin{abstract}
Software engineering is a rapid development field of computer. How to set up and optimize professional course system, teaching plan and how to improve the teaching methods to cultivate the practice software engineers meeting the immediate social needs with strong practical ability and innovation consciousness has been the problem that software engineering now faces with. Based on the analysis of software engineering courses teaching situation and software quantity curriculum, study the teaching methods of software engineering, broaden and refine the methods and ways for the cultivation of the software engineering students. Optimize teaching content reform, and escape the shackles of traditional teaching, benefit the students in practice and innovation ability training. This paper shows how the combination of theory and practice. In this way, students can have a perceptual knowledge on both sides, which helps mobilize their initiative in learning, so that to achieve the purpose of improving their abilities for combining theory with practice, analyzing and solving problems as well as practical learning.
\end{abstract}

\section{Introduction}

With the rapid development of software industry, software engineering has promoted to be the popular major at present. However, in the same time, it is a very difficult subject which has rich content concerning communication engineering, computer technology, computer education and economic management [1]. In addition, as the key technology of global information development, software engineering requires practitioners with the general and comprehensive knowledge. The fields for research must be extended from many aspects and angles, for instance, management, tools and techniques $[2,3]$. Software engineering is a practical and comprehensive professional course, compared with other professional education curriculum, there are some problems in practice part during teaching [4], it directly affects the education quality and the teaching effect. Therefore, it is very important to strengthen the innovation and reform about practice teaching content of software engineering actually. Software engineering has developed for many years and accumulated many software development technology and methods [5]. Combining the requirements for software engineering talents, we consider that the major should emphasize not only the thought and method, but also the process concept and application ability. Therefore, our first consideration is to update continuously and to enrich the teaching content. We plan to foster the ability of software development, project management skills and the ability of solving problem in the process of the project development, testing and management. Software engineering has developed for many years and accumulated many software development technology and methods. Combining the requirements for software engineering talents, we consider that the major should emphasize not only the thought and method, but also the process concept and application ability [6, 7]. Therefore, our first consideration is to update continuously and to enrich the teaching content. We plan to foster the ability of software development, project management skills and the ability of solving problem in the process of the project development, testing and management.

At present, the computer industry requires inter-disciplinary software engineers who can mater the software development technology and have the knowledge of project management. Because of this, 
we must position once again about the objectives of training, and programs of courses in software engineering teaching [8]. Training objective of software engineering courses should be targeted at social demands so as to enable the students to play an important role in the industry $[9,10]$. Therefore, not only the fundamentals, methods and techniques in the field of software engineering should be focused, but also the importance and necessity of development and management for software process development should be more emphasized. In particular, we should add the development process and management of software engineering into the normal teaching content and at the same time, supplemented with some class discussion and practice.

\section{Teaching Methods}

With the development of software engineering subject, new concepts, new technologies and new methods are constantly emerging, three points about the trend of teaching development of software engineering was shown in Fig .1.

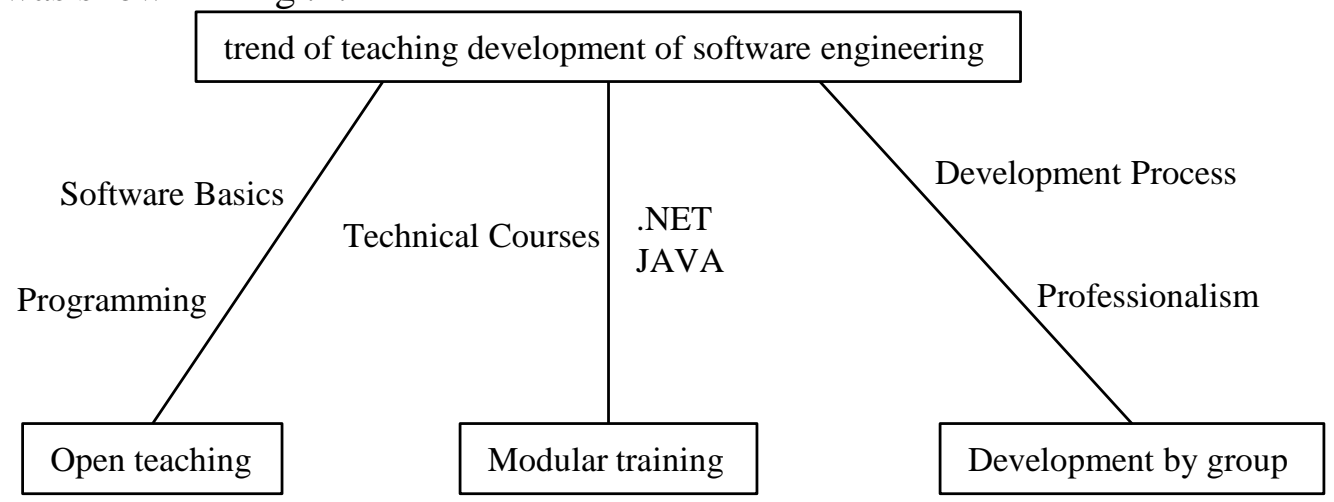

Figure. 1 Trend of teaching development of software engineering

- Open teaching: with the formation of industry framework, industry development and global integration of technology, the teaching for software engineering will no longer be confined to a book or a case and it will claim that the students cooperate and innovate properly with the integrated tools.

- Modular training: there is a new challenge in the field of software engineering because of increase in the complexity of IT environment and the remnant system in history. The modular thought can appropriately make acceleration in various software component and software application and improve the flexibility of software.

- Development by group: software engineering environment in group enables students experience in software development process which is in order, under control, collaborative. And in the process of analyzing, solving problems and coordinating, eliminating conflicts, the students could also share the final success.

\section{Reform of Teaching Content}

According to the teaching experience, mainly constructs a clear-level teaching practical system and content so as to meet the need of training plan on outstanding software engineer, and summing up the previous experience, then to form practical content system of the major.

Research and practice in practice teaching mode. By guiding the students to simulate the project practice, to form the level of practice teaching content and process and then to improve their interests to make the best teaching effect.

Build an environment which is suitable for developing software in group. Only in a qualified environment could the students master the thought and method of software engineering.Therefore, this part is the most important one during the project.

We are making a research combining actual project cases-driven model and integrated development tools SDM, and there are two aspects need to do. First one is the breakthrough on original practical teaching mode and solving the problem in abstract course content with actual 
projects. The other is that doing the teaching practice in an environment for the development of software engineering so as to ensure the students acquire actual practice.

After the further analysis in the body knowledge of software engineering, according to the the existing school conditions and the overall plan of software engineering courses, we have established software engineering curriculum system (it was shown in Fig. 2), which combines basic knowledge, advanced technique, engineering practice and software engineering body of knowledge released by IEEE.

\begin{tabular}{|c|c|c|c|c|c|c|c|c|}
\hline \multicolumn{9}{|c|}{ Curriculum practice based on project and case drive } \\
\hline \multicolumn{5}{|c|}{ object-oriented techniques and languages } & \multicolumn{4}{|c|}{ iteratively developed (RUP, Rational Rose, CVS) } \\
\hline requirement & design & realization & test & evolution & process & quality & $\begin{array}{c}\text { configuration } \\
\text { management }\end{array}$ & $\begin{array}{c}\text { project } \\
\text { management }\end{array}$ \\
\hline
\end{tabular}

Figure. 2 Software engineering curriculum system

The content of the three levels of curriculum system are theoretical foundation, knowledge application and practice exercises. Unit of practice curriculum knowledge covers software engineering body of knowledge including software requirement, design, realization, test, evolution, process, quality, configuration management and software project management. The next is application part, that is to enable the students to master the advanced software engineering methods and technology at present after integrating into the best practices of enterprises and the actual case which covering IEEE software engineering standard. In practice exercises part, it requires the students to develop a software system with a certain scale of cooperation on a team. And need to build an environment for software development so as to guide the students to solve the problems when developing software by applying the idea of software engineering and current technology.

\section{Implementation Method}

For the effective construction of multi-level architecture teaching, we combine the teaching plan and practice closely by four steps (see Fig .3).

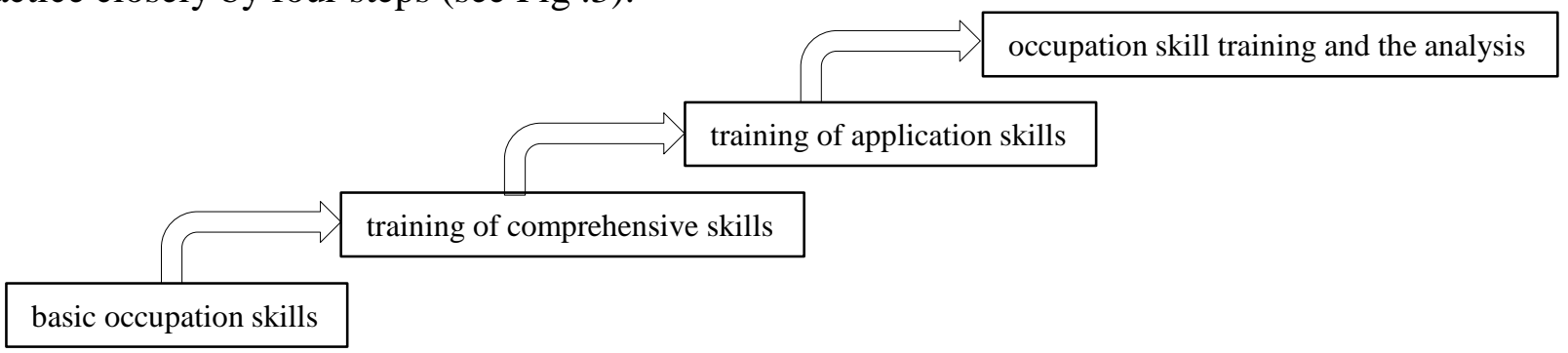

Figure. 3 Teaching plan and practice closely by four steps

The first step is basic occupation skills. That is to add the introduction of .NET and JAVA as the practice content so as to enable the students to know the elementary knowledge of object oriented development.

The second step is the training of comprehensive skills. In order to let students know elementary knowledge of application system development and the work of NET in system development. In the same way, to ensure them to design some easy interfaces and make some database designs.

The third step is the training of application skills. Through the first two stages of progressive cognitive, the students could learn object-oriented language with the ability being highly targeted. At the same time, the teachers could also make some adjust properly on practice teaching content and the relevant technology for constructing of application system and then make analysis and explanation so as to guide the students to well know how to use the new techniques correspondingly. At last, the students could make analysis and then accomplish the realization. On one hand, the step could 
enhance the combat ability of students. On the other hand, it could also enhance the ability of team cooperation.

The last step is occupation skill training and the analysis of the case about software development. According to the relevant technology and methods, the students make systems analysis, system design, system implementation and system test in view of the practical application system project. And then, they make evaluation and test on the project from the other group combining the relevant technology in software engineering. Eventually, the final aim that the formation of team consciousness could help them enhance and improve in the further practical link will be achieved.

\section{Summary}

There are great meaning in making a detailed research on the approach and method of the development of under- graduated innovative talents in software engineering and speeding up the improvements in educational quality.

According to the requirements of training plan and the intensify in practical teaching, the content of courses reform in software engineering will meet the current development trend and social demands in software engineering talents. We should show more systematization and engineering in the practice of teaching content and guide the students to combine the interactive discussion and exploration learning together in educational methods. We should also build an environment which is suitable for practical teaching for the under-graduated students and could either help them master the basic knowledge, advanced methods and the latest technology in software engineering. Our final aim is to make sure that the students have strong ability of knowledge development and then lay a solid foundation for the further professional learning. At the same time, through the practical teaching part, the students will have strong combat capability and save much time in development tools and environment when they come into the period for graduation design, which could help them make requirement analysis and design on application of project so as to develop the application system meeting the actual demands.

Actual project and case drive practice teaching mode has a strong maneuverability. According to the thinking habit for software engineering and the interests of the students, valuing the vitality and creative desire of the students in the learning process could make sure that they will have perceptual learning effectively. What's more, it could also provide the effective reference to the road of reform and innovation in major computer science. This study focuses on the effectiveness and carries forward concrete implementation of the training plan for excellent engineers in computer education. We hope that the result would be comprehensively promoted among the college and reflect its values.

\section{Acknowledgements}

This work was supported by teaching reform project of Jiangsu University of Technology (JG13012、 JG13014、11610311415).

\section{References}

[1] L. Sun, C. Liu, C. Zhang, B. T. Peng and Y. Chen: In Frontier and Future Development of Information Technology in Medicine and Education, (Xining, China, July 19-21 2013). Vol. 269. p. 1603-1608.

[2] M. Kropp and A. Meier: 2014 IEEE Global Engineering Education Conference, (Istanbul, Turkey, April 3-5, 2014). p.1019-1022.

[3] C. Wohlin, P. Runeson, M. Höst, M. C. Ohlsson, B. Regnell and A. Wesslén: Experimentation in Software Engineering (Springer, Germany 2012). 
[4] C. Deiters, C. Herrmann, R. Hildebrandt, E. Knauss, Marco Kuhrmann, A. Rausch, B. Rumpe and K. Schneider: 2011 6th IEEE International Conference on Global Software Engineering, (Helsinki, Finland, August 15-18, 2011). p. 156-160.

[5] J. Vanhanen, T O A. Lehtinen and C. Lassenius: 2012 First International Workshop on Software Engineering Education based on Real-World Experiences, (Zurich, Switzerland, June 09-11, 2012). p. 29-32.

[6] W Q. Qu, Y F. Zhao and M. Wang: 2014 9th International Conference on Computer Science \& Education, (Vancouver, Canada, Augurs 22-24, 2014). p. 855-860.

[7] F F. Tsui: Essentials of Software Engineering (Jones and Bartlett Publishers, Canada 2013).

[8] Y. Tao, G. Liu, J. Mottok,R. Hackenberg and G. Hagel: 2014 IEEE Global Engineering Education Conference, (Istanbul, Turkey, April 03-05, 2014). p. 983-986.

[9] M. Nordio, C. Ghezzi, B. Meyer, D N. Elisabetta, T. Giordano, T. Julian, A. Nazareno and K. Vidya: Proceedings of the 2011 Community Building Workshop on Collaborative Teaching of Globally Distributed Software Development, (ACM, 2011). p. 36-40.

[10]P. Runeson, M. Host, A. Rainer and B. Regnell: Case Study Research in Software Engineering: Guidelines and Examples (John Wiley and Sons, America 2012). 